\title{
Dienogest in the Treatment of Endometriosis
}

\author{
Kazushige Adachi*, Akiko Otake and Yoshimitsu Yamamoto \\ Department of Obstetrics and Gynecology, Minoh City Hospital, Japan
}

Submission: September 6, 2017; Published: September 11, 2017

*Corresponding author: Kazushige Adachi, Department of Obstetrics and Gynecology, Minoh City Hospital, 5-7-1 Kayano, Japan, Tel: +81-72-728-2001, FAX: +81-72-728-8495, Email: k.adachi@minoh-hp.jp

\begin{abstract}
Endometriosis is a prevalent chronic disease in up to $10 \%$ of women of reproductive age and often causes pain symptoms. In some patients, these symptoms negatively affect quality of life for a long time. Dienogest is an oral progestin that was recently approved for the treatment of endometriosis. It is allowed for long-term administration with a favorable safety and tolerability profile. Dienogest $2 \mathrm{mg} / \mathrm{day}$ was superior to placebo in relieving pain symptoms in patients with endometriosis, equivalently effective to gonadotropin releasing hormone agonist (GnRHa). The size of endometriomas was reduced by use of dienogest. Postoperative administration of dienogest showed the efficacy in relieving pain and suppressing recurrence of endometrioma in patients with endometriosis. Dienogest was also effective in relieving symptoms in women with deep infiltrating endometriosis (DIE) or extragenital endometriosis. Dienogest is an alternative for the treatment of endometriosis because of its efficacy, safety and tolerability.
\end{abstract}

Keywords: Dienogest; Endometriosis

Abbreviations: GnRHa: Gonadotropin Releasing Hormone Agonist; DIE: Deep Infiltrating Endometriosis;

\section{Introduction}

Endometriosis is a common disease in up to $10 \%$ of women of reproductive age. It often causes symptoms such as dysmenorrhea, chronic pelvic pain, dyspareunia and dyschezia [1]. It is also associated with ovarian endometrioma which requires surgery for both diagnosis and treatment. However, recurrence rates are approximately $30-50 \%$ within 5 years after surgery [2]. Dienogest is a new synthetic oral progestin that was approved for the treatment of endometriosis [3].

It works by preventing the growth of the endometrium and suppressing estrogen production [4]. Additionally, it is allowed for long-term administration unlike gonadotropin releasing hormone agonist (GnRHa) [5]. Long-term dienogest showed a favorable safety and tolerability profile, including a low incidence of hypoestrogenic effects and minimal change in bone mineral density [6]. The aim of this study is to review literature and assess the efficacy of dienogest in the treatment of endometriosis.

\section{Pain Relief}

In a 12-week randomized placebo-controlled study involving 198 women, dienogest $2 \mathrm{mg}$ /day was more effective than placebo for reducing endometriosis-associated pelvic pain [7]. A study of one year-treatment demonstrated that dienogest showed pelvic pain reduction through the treatment period [5] and the decrease of pelvic pain persisted for at least 24 weeks after treatment cessation [8]. Dienogest $2 \mathrm{mg}$ /day for 24 weeks was equivalently effective to subcutaneous leuprolide acetate 3.75 mg every 4 weeks [9] or intranasal buserelin acetate $900 \mathrm{mg} /$ day [10] in relieving the painful symptoms of endometriosis.

Postoperative administration of dienogest showed a significant higher pelvic pain reduction than the expectant management group until 24 months of follow-up in a multicenter study [11]. Dienogest prevented pelvic pain recurrence as effectively as GnRHa after laparoscopic surgery for endometriosis [12]. Dienogest plus estradiol valerate is significantly more effective than levonorgestrel-releasing intrauterine device in reducing pelvic pain after surgery for endometriosis [13].

\section{Ovarian Endometrioma}

Treatment of dienogest over 12 months decreased the size of endometrioma to approximately $30 \%$ of the initial sizes [14] and the similar effect was also observed in the patients of recurrent endometrioma [15].

There has been reported the efficacy of postoperative dienogest on endometrioma recurrence. A postoperative dienogest treatment versus a control group showed a significant difference in recurrence at $12(0 \%$ vs. $16.5 \%)$ or 24 months $(0 \%$ vs. $24.0 \%$ ) [11]. Although recurrence was not seen in patients 


\section{Global Journal of Reproductive Medicine}

with dienogest, no medication group showed recurrence up to $50 \%$ at 5 years after surgery [16]. No significant difference was observed in the postoperative recurrence rate between the dienogest and goserelin (subcutaneous $1.8 \mathrm{mg}$ every 4 weeks) group [17].

\section{Deep Infiltrating Endometriosis (DIE)}

DIE can affect the bowel and the urinary tract and causes severe pain. Dienogest is as effective as surgical treatment in relieving pain in more than $90 \%$ of women with DIE at one year follow-up [18]. Postoperative administration of dienogest significantly reduced the endometriosis-related pain in the DIE patients [19]. A prospective cohort study demonstrated that dienogest for 12 months was effective to control pain related to DIE, even without reducing the volume of DIE nodules [20].

\section{Extragenital Endometriosis}

There are a few pilot studies describing the efficacy of dienogest on extragenital endometriosis. Four cases with colon endometriosis, treated with dienogest for over 6 months, exhibited their size reduction and pain relief related with the legions [21]. By treatment of dienogest for 12 months, symptoms were improved and the nodules reduced in size in 6 cases of bladder endometriosis [22].

\section{Conclusion}

The above studies suggested that dienogest is an alternative as first-line therapy for relieving pain and suppressing recurrence in patients with endometriosis. However, there is still a need to establish the effect of long-term treatment with dienogest and the recurrence after its discontinuation. Moreover, there were no studies comparing the efficacy and safety between dienogest and combined oral contraceptives which are also effective in the treatment of endometriosis. Further randomized investigations are necessary to elucidate strategies of dienogest for the treatment of endometriosis.

\section{References}

1. Giudice LC, Kao LC (2004) Endometriosis. Lancet 364 (9447): 17891799.

2. Vercellini P, Somigliana E, Daguati R, Vigano P, Meroni F, et al. (2008) Postoperative oral contraceptive exposure and risk of endometrioma recurrence. Am J Obstet Gynecol 198(5): 504.e1-5.

3. Sasagawa S, Shimizu Y, Kami H, Takeuchi T, Mita S, et al. (2008) Dienogest is a selective progesterone receptor agonist in transactivation analysis with potent oral endometrial activity due to its efficient pharmacokinetics profile. Steroids 73(2): 222-231.

4. Klipping C, Duijkers I, Remmers A, Faustmann T, Zulth C, et al. (2012) Ovulation-inhibiting effects of dienogest in a randomized, dosecontrolled pharmacodynamics trail of healthy women. J Clin Pharmacol 52(11): 1704-1713.

5. Seitz C, Gerlinger C, Faustmann T, Strowitzki T (2009) Safety of dienogest in the long-term treatment of endometriosis: a one-year, open-label, follow-up study. Fertil Steril 92 (23): S107.

6. Strowitzki T, Faustmann T, Gerlinger C, Schumacher U, Ahlers C, et al. (2015) Safety and tolerability of dienogest in endometriosis: pooled analysis from the European clinical study program. Int J Women Health 7: 393-401.
7. Strowitzki T, Faustmann T, Gerlinger C, Seitz C (2010) Dienogest in the treatment of endometriosis-associated pelvic pain: a 12 week, randomized, double-blind, placebo-controlled study. Eur J Obstet Gynecol Reprod Biol 151(2): 193-198.

8. Petraglia F, Hornung D, Seitz C, Faustmann T, Gerlinger C, et al. (2012) Reduced pelvic pain in women with endometriosis: efficacy of longterm dienogest treatment. Acta Gynecol Obstet 285(1): 167-173.

9. Strowitziki T, Marr J, Gerlinger C, Faustmann T, Seitz C (2010) Dienogest is as effective as leuprolide acetate in treating the painful symptoms of endometriosis: a 24-week, randomized, multicenter, open-label trial. Human Reprod 25(3): 633-641.

10. Harada T, Momoeda M, Taketani Y, Aso T, Fukunaga M, et al. (2009) Dienogest is as effective as intranasal buserelin acetate for the relief of pain symptoms associated with endometriosis: a randomized, doubleblind, multicenter, controlled trial. Fertil Steril 91(3): 675-681.

11. Adachi K, Takahashi K, Nakamura K, Otake A, Sasamoto N, et al. [2016] Post -operative administration of dienogest for suppressing recurrence of disease and relieving pain in subjects with ovarian endometriomas. Gynecol Endcriol 32(8): 646-649.

12. Lee DY, Lee JY, Seo JW, Yoon BK, Choi D (2016) Gonadotropin-releasing hormone agonist with add-back treatment is as effective and tolerable as dienogest in preventing pain recurrence after laparoscopic surgery for endometriosis. Arch Gynecol Obstet 294 (6): 1257-1263.

13. Morelli M, Sacchinelli A, Venturella R, Mocciaro R, Zullo F (2013) Postoperative administration of dienogest plus estradiol velerate versus levonorgestrel-releasing intrauterine device for prevention of pain relapse and disease recurrence in endometriosis patients. J Obstet Gynecol Res 39(5): 985-990.

14. Sugimoto K, Nagata C, Hayashi H, Yanagida S, Okamoto A (2015) Use of dienogest over 53 weeks for the treatment of endometriosis. J Obstet Gynecol Res 41(12): 1921-1926.

15. Park SY, Kim SH, Chae HD, Kim CH, Kang BM (2016) Efficacy and safety of dienogest in patinets with endometriosis: A single-center observation study over 12 months. Clin Exp Reprod Med 43 (4): 215220.

16. Ouchi N, Akira S, Mine K. Ichikawa M, Takeshita T (2014) Recurrence of ovarian endometrioma after laparoscopic excision: Risk factors and prevention. J Obstet Gynecol Res 40(1): 230-236.

17. Takaesu Y, Nishi H, Kojima J, Sasaki T, Nagamatsu Y, et al. (2016) Dienogest compared with gonadotropin-releasing hormone agonist after conservative surgery for endometriosis. J Obstet Gynecol Res 42(9): 1152-1158.

18. Berlanda N, Somigliana E, Frattaruolo MP, Buggio L, Dridi D, et al (2017) Surgery versus hormonal therapy for deep endometriosis: is it a choice of the physician? Eur J Obstet Gynecol Reprod Biol 209: 67-71.

19. Yamanaka A, Hada T, Matsumoto T, Kanno K, Shirane A, et al. (2017) Effect of dienogest on pain and ovarian endometrioma occurrence after laparoscopic resection of uterosacral ligaments with deep infiltrating endometriosis. Eur J Obstet Gynecol Reprod Biol 216: 51-55.

20. Leonardo-Pinto JP, Benetti-Pinto CL, Cursino K, Yela DA (2017) Dienogest and deep infiltrating endometriosis: The remission of symptoms is not relate to endometriosis nodule remission. Eur J Obstet Gynecol Reprod Biol 211: 108-111.

21. Harada M, Osuga Y, Izumi G, Takamura M, Takemura Y, et al. (2011) Dienogest, a new conservative strategy for extragenital endometriosis: a pilot study. Gynecol Endocrinol 27(9): 717-720.

22. Angioni S, Nappi L, Pontis A, Sedda F, Luisi S, et al. (2015) Dienogest. A possible conservative approach in bladder endometriosis. Results of a pilot study. Gynecol Endocrinol 31(5): 406-408. 
This work is licensed under Creative

Commons Attribution 4.0 Licens

DOI: 10.19080/GJORM.2017.02.555586
Your next submission with Juniper Publishers will reach you the below assets

- Quality Editorial service

- Swift Peer Review

- Reprints availability

- E-prints Service

- Manuscript Podcast for convenient understanding

- Global attainment for your research

- Manuscript accessibility in different formats

( Pdf, E-pub, Full Text, Audio)

- Unceasing customer service

Track the below URL for one-step submission https://juniperpublishers.com/online-submission.php 